\title{
The influence of different surface treatment protocols and bonding agents on the repair microtensile bond strength of six- month' aged composite: An in vitro study
}

A influência de diferentes protocolos de tratamento de superfície e agentes de união na resistência de união à microtração de reparo de compósito envelhecido por seis meses: um estudo in vitro

Reham S. SALEH ${ }^{1}$, Engie M. SAFWAT ${ }^{1}$

1 - Restorative and Dental Materials Department - National Research Centre - Egypt.

\begin{abstract}
Objective: To compare the effect of three surface treatment protocols and two intermediate agents on repairing aged composite, regarding microtensile bond strength ( $\mu \mathrm{TBS}$ ) and mode of fracture, at two time intervals. Material and methods: Six-month aged microhybrid composite blocks, were randomly distributed into three groups, subjected to; Fine, Super Fine grit diamond burs or Erbium- Yag Laser surface treatment. Each block had both One Coat bond SL (Bond) and Brilliant Flow flowable composite (Flow) intermediate agents, alongside. Blocks were incrementally repaired using nanohybrid composite, cut into beams, then randomly subjected either immediately (IM) to $\mu$ TBS test or after thermocycling (TC) for 5000 cycle. Mode of failure was determined using stereomicroscope. Data were analyzed through three-way ANOVA followed by pairwise comparison with Bonferroni correction. Kruskal Wallis test compared groups for failure mode analysis $(\alpha=0.05)$ Results: Super Fine grit showed the highest mean $\mu$ TBS compared to control for both intermediate agents, IM and after TC at $\mathrm{P}<0.05$. No difference between Fine grit and Laser application for all groups ( $P>0.05)$. IM, Bond showed the highest $\mu$ TBS compared to TC, Flow for all tested groups. Beams roughened with Fine and Super Fine burs showed significantly lower adhesive failures than those roughened with Laser. Flow suffers significantly higher adhesive failure than those with Bond. For TC tested groups; beams with Super Fine bur and Bond showed significantly lower adhesive failure at $\mathrm{P}=0.029$. Conclusion: Super Fine grit and Bond provide the highest $\mu \mathrm{TBS}$ and the least adhesive failure; moreover TC resulted in significant decrease in $\mu \mathrm{TBS}$.
\end{abstract}

\section{KEYWORDS}

Aged composite repair; Erbium- Yag Laser; Fine grit diamond bur; Microtensile bond strength; Super Fine grit diamond bur.

\section{RESUMO}

Objetivo: Comparar o efeito de três protocolos de tratamento de superfície e dois agentes intermediários no reparo de compósito envelhecido, quanto à resistência à microtração ( $\mu$ TBS) e modo de fratura, em dois intervalos de tempo. Material e métodos: Blocos de compósito microhíbrido envelhecidos por seis meses, foram distribuídos aleatoriamente em três grupos, submetidos a; Pontas diamantadas de granulação Fina, Superfina ou tratamento de superfície com laser de Erbio-Yag. Cada bloco tinha ambos os agentes intermediários One Coat bond SL (Adesivo) ao lado de Brilliant Flow (Resina Fluida). Os blocos foram reparados de forma incremental usando compósito nanohíbrido, cortados em palitos e, em seguida, submetidos aleatoriamente imediatamente (IM) ao teste de $\mu$ TBS ou após termociclagem (TC) por 5000 ciclos. O modo de falha foi determinado usando estereomicroscópio. Os dados foram analisados por meio de ANOVA de três fatores, seguida de comparação pareada com correção de Bonferroni. O teste de Kruskal Wallis comparou os grupos para análise do modo de falha $(\alpha=0,05)$. Resultados: a granulação Superfina apresentou a maior média de $\mu$ TBS em comparação com o controle para ambos os agentes intermediários, IM e após TC (P $<0,05)$. Não houve diferença entre granulação fina e aplicação de laser para todos os grupos (P>0,05). IM, Adesivo apresentou a $\mu$ TBS mais alta em comparação com TC, Resina Fluida para todos os grupos testados. Os palitos asperizados com pontas de granulações Fina e Superfina apresentaram falhas adesivas significativamente menores do que as asperizadas com Laser. Resina Fluida sofreu falhas adesivas significativamente maiores do que aquelas com Adesivo. Para grupos testados TC; palitos tratados com ponta Superfina e Adesivo apresentaram falha adesiva significativamente menor com $P=0,029$. Conclusão: a granulação Superfina e o Adesivo fornecem a maior $\mu$ TBS e o mínimo de falha adesiva; além disso, o TC resultou em uma diminuição significativa da $\mu$ TBS.

\section{PALAVRAS-CHAVE}

Reparo de compósito envelhecido; Laser de Erbio-Yag; Ponta diamantada de granulação fina; Resistência à microtração; Ponta diamantada de granulação superfina. 


\section{INTRODUCTION}

T $\mathrm{n}$ conservative dentistry, there is a growing 1 trend towards repairing defective composite restorations instead of complete replacement. Composite repair not only increase the longevity of restorations but also save sound tooth structure and avoid trauma from restorative procedures [1-5].

Due to absence of unpolymerized surface layer in aged composite restoration, several methods have been suggested to improve the composite-composite bond [6,7], such as surface roughening with diamond burs, acid etching or air abrasion with aluminum oxide particles. These surface treatments provide surface irregularities which promote micro-mechanical interlocking between the substrate surface and the repair resin. [5,7-10] In most clinical studies, partial removal of the old composite was done using coarse diamond bur [1,11-13], however, using either medium or fine grit diamond bur can produce more reliable repair bond strength than using coarse diamond bur. $[13,14]$ on the other hand, Erbium laser has been recently suggested for surface roughness of the old composite by ablation mechanism, which can be used in the process of repair [15-17].

After surface treatment, the next step is the application of bonding gents in order to enhance chemical bond as experimentally proved in many literatures. [1,2,8,10,18,19]

In earlier studies, promising results of composite repair were obtained using different protocols; however these results were questionable as most tests were performed on non-aged substrates which didn't represent the real clinical situation. In addition, they often depend on using the same type of composite for the substrate and the repair material $[5,6,11]$.

Based on the previous drawbacks, this study aimed to (a) investigate different surface treatments of aged composite, in order to obtain reliable repair bond strength, (b) investigate the effect of different intermediate agents on the repair bond strength and (c) assess the long term durability of the repair bond strength.
The null hypothesis was examined, first; that there is no difference in $\mu$ TBS between all surface treated protocols and intermediate agents whether tested IM or after TC, second: there is no difference in the mode of failure in all groups.

\section{MATERIAL AND METHODS}

The composite type, chemical compositions, percentage of filler loading and manufacturers of the materials used in this study are listed in table I.

Table I - The composite type, matrix, filler, load percentage and manufacturers of the materials used:

\begin{tabular}{|c|c|c|c|c|}
\hline $\begin{array}{l}\text { The com- } \\
\text { posite type }\end{array}$ & Matrix & Filler & $\begin{array}{l}\text { Load } \\
\text { percent }\end{array}$ & Manufacturer \\
\hline $\begin{array}{l}\text { Opallis (mi- } \\
\text { crohybrid) }\end{array}$ & $\begin{array}{l}\text { Bis-GMA } \\
\text { Bis-EMA } \\
\text { TEGDMA }\end{array}$ & $\begin{array}{l}\text { Barium- Aluminum } \\
\text { glass, silanized si- } \\
\text { lica, pigments and } \\
\text { silicas particles } \\
(40 \mathrm{~nm}-3 \mu \mathrm{m})\end{array}$ & $57.8 \% \mathrm{vol}$ & $\begin{array}{l}\text { FGM dental pro- } \\
\text { ducts, Joinville, } \\
\text { SC, brazil. }\end{array}$ \\
\hline $\begin{array}{l}\text { BrilliantEver } \\
\text { Glow (na- } \\
\text { nohybrid) }\end{array}$ & $\begin{array}{l}\text { Bis-GMA } \\
\text { Bis-EMA } \\
\text { TEGDMA }\end{array}$ & $\begin{array}{c}\text { Silica glass, Zinc } \\
\text { oxide }(0.02-1 \mu \mathrm{m}) \text {. }\end{array}$ & $74 \% \mathrm{vol}$ & $\begin{array}{l}\text { Coltène/Whale- } \\
\text { dent AG, Altstät- } \\
\text { ten, Swizerland. }\end{array}$ \\
\hline EtchantGelS & $\begin{array}{c}\text { Phosphoric acid } \\
35 \% .\end{array}$ & - & - & $\begin{array}{l}\text { Coltène/Whale- } \\
\text { dent AG, Altstät- } \\
\text { ten,Swizerland. }\end{array}$ \\
\hline $\begin{array}{l}\text { One coat bond } \\
\text { SL (Bond) }\end{array}$ & $\begin{array}{c}\text { Phosphoric acid } \\
\text { 35-40\%, HEMA, } \\
\text { HPMA,UDMA, } \\
\text { MA modified } \\
\text { PLA, polyalke- } \\
\text { noate and } \\
\text { photoinitiators. }\end{array}$ & - & - & $\begin{array}{l}\text { Coltène/Whale- } \\
\text { dent AG, Altstät- } \\
\text { ten, Swizerland. }\end{array}$ \\
\hline $\begin{array}{l}\text { Brilliant Flow } \\
\text { flowable } \\
\text { compsite } \\
\text { (Flow) } \\
\text { (nanofilled) }\end{array}$ & $\begin{array}{l}\text { Bis-GMA } \\
\text { Bis-EMA } \\
\text { TEGDMA }\end{array}$ & $\begin{array}{c}\text { Barium glass, } \\
\text { silanized silica } \\
\text { (0.6um) }\end{array}$ & $42 \% \mathrm{vol}$ & $\begin{array}{l}\text { Coltène/Whale- } \\
\text { dent AG, Altstät- } \\
\text { ten, Swizerland }\end{array}$ \\
\hline
\end{tabular}

Abbreviations: Bis-GMA: bisphenol A diglycidyl methacrylate; Bis-EMA: bisphenol A diglycidyl methacrylate ethoxylated; TEGDMA: triethylene glycol dimethacrylate, UDMA: urethane dimethacrylate; HEMA: hydroxyethyl metacrylate; HPMA: hydroxyl propyl methacrylate; MA modified PLA: methacrylate modified polyacrylic acid.

\section{Specimen preparation:}

Eight microhybrid cylinder-shaped composite blocks (Opallis, shade A2) were fabricated using a Teflon mold (8mm diameter x $4 \mathrm{~mm}$ height) $[12,18,20-22]$, such that each 2-mm-thick increment was separately cured for 40 seconds using Elipar LC curing unit 
(3M, USA ) with an intensity of $600 \mathrm{~mW} / \mathrm{cm}^{2}$ [7,11,12,18,20-22]. All blocks were stored in artificial saliva for six months [23].

\section{Repair procedures:}

Aged microhybrid composite blocks were randomly divided into four groups (two blocks each); such that, one surface of each block in the first group was roughened with a Fine grit diamond bur (Microdont, Brazil) $[14,24]$ and those of the second group with a Super Fine grit diamond bur (Microdont ,Brazil ) [18] for 10 seconds under water cooling. Correspondingly, one surface of each block the third group was irradiated by Erbium-Yag Laser (Fotona LightWalker AT), emitting $298 \mathrm{~nm}$. The parameters used were: $2 \mathrm{~W}$ output power with $200 \mathrm{MJ}$ energy and $10 \mathrm{~Hz}$ frequency in a super short pulsed mode (SSP); pulse duration 50 micro seconds. Laser was used with gentle sweeping motion at a working distance of 1 $\mathrm{mm}$ using $\mathrm{HO} 2$ Tipless hand piece and the surfaces were treated at irradiation condition of $50 \%$ water and $60 \%$ air with air/water spray $[15,16,19]$. A forth group had no surface treatment (control).

After surface treatment, blocks of all groups were etched with 35\% phosphoric acid gel (Etchant Gel S) for 30 seconds, rinsed with water for 30 seconds and air dried for 10 seconds.

Then each block in all surface treated groups received both Bond and Flow intermediate agents side by side in the same block for standardization. Both intermediate agents were applied in thin layer using a small brush, air thinned and photopolymerized according to the manufacturer's instructions of each intermediate agent $[10,18,21]$.

Each of the eight block was incrementally repaired with two layers ( $2 \mathrm{~mm}$ thickness each) using Brilliant Ever Glow nanohybrid composite in a Teflon mold ( $8 \mathrm{~mm}$ diameter $\mathrm{x} 8 \mathrm{~mm}$ height).
Each layer was light cured for 40 seconds using Elipar LC curing unit (3M, USA) according to manufacturer's instructions. After removal of the composite blocks from the mold, additional curing was done for 40 seconds. Finally, blocks were color coded in red and blue for labeling Bond and Flow intermediate agents respectively (Figure 1).

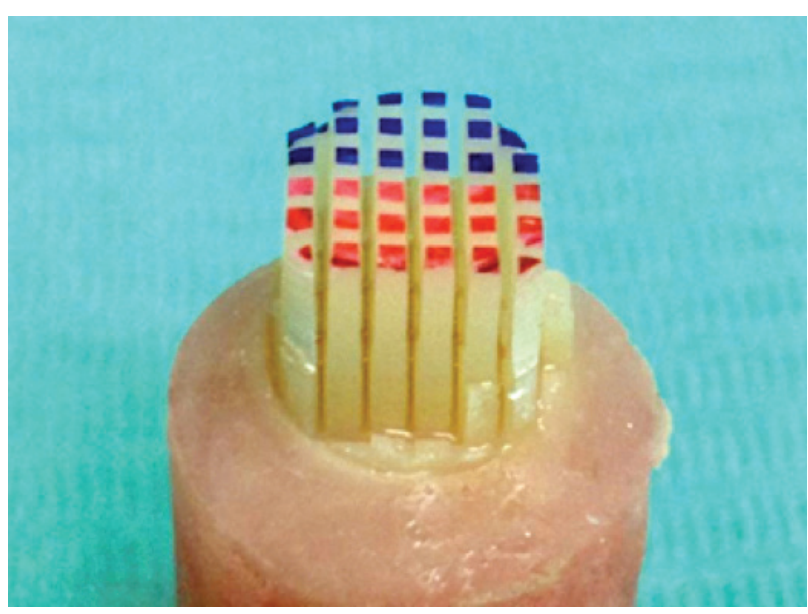

Figure 1 - The repaired composite block with serial sections beams, beams are color coded in red and blue representing Bond and Flow intermediate agents respectively.

Beam specimens' preparation for microtensile test:

The repaired composite resin blocks were sectioned with a diamond saw in a very precision cutting machine at low speed, under water cooling (Labcut 1010; Extec Corp., Enfield, CT, USA). This precision milling device was used to reduce the stress at the adhesive interface, as hand trimming had been reported as a defect inducing factor which elicits stress concentration at the adhesive interface $[5,11]$.

First, the blocks were glued with cyanoacrylate adhesive (Super Bonder Gel, Loctite Ltd., São Paulo, Brazil) on a metallic base which was attached to the sectioning machine. Then the blocks were positioned perpendicular to the diamond disc of the machine. 
The peripheral slices which measure approximately $0.5 \mathrm{~mm}$ were discarded as they might influence the results either the excess or insufficient amount of resin at the margins. Thus, the central parts of the specimens were used for the experiments. Non trimmed rectangular beams with an adhesive surface area of $1 \pm 0.1$ $\mathrm{mm} 2$ and a length of about $8 \mathrm{~mm}$ were achieved from each block (Figure 1). Nearly thirty beams were obtained from each block.

Beams were randomly divided into another two groups according to the time of microtensile bond strength testing; either IM or after TC for 5000 cycles between $5-55^{\circ} \mathrm{C}$ with a dwell time of 20 seconds. [2,19,20,25,26] random allocation was done in order to decrease bias between groups.

\section{Microtensile bond testing:}

At a crosshead speed of $0.5 \mathrm{~mm} /$ minute in a universal testing machine (Controls, Milano, Italy) each beam was loaded in tension. The load at failure was recorded in Newtons (N). In order to express bond strength values in Mega Pascals (MPa), the cross-sectional area at the site of fracture was measured to the nearest $0.01 \mathrm{~mm}$ using a digital caliper.

\section{Failure mode analysis}

A stereomicroscope (SMZ645, Nikon Co, Tokyo, Japan) at 50x magnification was used to evaluate and record the failure modes of the fractured beams. The mode of failure was classified as cohesive (either within the aged or the new repaired composite), adhesive or mixed (a combination of cohesive/ adhesive failure modes). The number of beams representative of the three failure patterns within each experimental subgroup was expressed as a percentage. [4,5,9,21,24,25,27]

\section{Statistical analysis:}

Data Explored for normality was obtained using Kolmogorov-Smirnov test. Three-way ANOVA was used to compare between tested surface treatments, intermediate agents and thermocycling followed by pairwise comparison with Bonferroni correction. Kruskal Wallis test was used to compare between different treatment protocol and different tested groups for failure mode analysis. $(\alpha=0.05)$ (IBM SPSS Statistics for Windows, Version 23.0. Armonk, NY: IBM Corp.)

\section{RESULTS:}

\section{Results of microtensile bond testing:}

Mean $\mu$ TBS and standard deviations are shown in table II. As shown, for aged composite; surface treatments, intermediate agents and thermocycling resulted in a significant effect on $\mu$ TBS at $\mathrm{P} \leq 0.001$. Among the three tested surface treatment protocols, Super Fine grit showed the highest statistically significant mean $\mu$ TBS for both intermediate agents (Bond and Flow) when tested IM or after TC at $\mathrm{P}<0.05$. For the IM tested beams, there was no statistical significant difference between Fine grit, Laser and control for Bond as intermediate agent, and between control and Fine grit for Flow as intermediate agent, meanwhile, Laser showed significantly higher $\mu$ TBS than control though not significantly different than Fine grit. On the other hand, for the TC tested samples and Bond as intermediate agent, there was no statistical significant difference among Fine grit, Laser and control, as well as, there was no statistically significant difference between all tested surface treatment protocols for Flow as intermediate agent.

For Fine grit surface treatment and after TC, beams with Flow as intermediate agent showed statistically lower $\mu$ TBS at $\mathrm{P} \leq 0.001$. As for Super Fine grit surface treatment, Bond TC tested beams had statistically higher $\mu$ TBS than those of Flow TC at $\mathrm{P}=0.01$, meanwhile, there was no statistically significant difference between tested groups for pretreatment with Laser at $\mathrm{P}=0.058$. 
Table II - Mean $\mu$ TBS (MPa) and standard deviations of control, Fine grit, Super Fine grit diamond burs and Laser application coupled with either Bond or Flow intermediate agent, tested IM and after TC.

\begin{tabular}{|c|c|c|c|c|c|c|c|c|c|c|}
\hline & & \multicolumn{2}{|c|}{ Control } & \multicolumn{2}{|c|}{ Fine Grit } & \multicolumn{2}{|c|}{ Super Fine Grit } & \multicolumn{2}{|c|}{ Laser } & \multirow{2}{*}{ P-value } \\
\hline & & Mean & SD & Mean & SD & Mean & SD & Mean & SD & \\
\hline \multirow{2}{*}{ IM } & Bond & $18.91^{\mathrm{bA}}$ & 9.71 & $25.66^{\mathrm{bA}}$ & 10.22 & $40.92^{\mathrm{aA}}$ & 10.28 & $28.53^{b}$ & 8.87 & $\leq 0.001^{*}$ \\
\hline & Flow & $12.49^{\mathrm{CAB}}$ & 4.60 & $22.12^{\text {bca }}$ & 11.19 & $34.95^{\text {АВ }}$ & 7.17 & $24.32^{b}$ & 7.47 & $\leq 0.001^{*}$ \\
\hline \multirow{2}{*}{ TC } & Bond & $12.49^{\mathrm{bAB}}$ & 5.15 & $20.39^{\mathrm{bA}}$ & 7.16 & $33.16^{\mathrm{AB}}$ & 8.91 & $21.04^{b}$ & 5.62 & $\leq 0.001^{*}$ \\
\hline & Flow & $6.76^{\mathrm{bB}}$ & 3.66 & $15.13^{\mathrm{abB}}$ & 3.87 & $22.75^{\mathrm{aB}}$ & 8.81 & $15.67^{\mathrm{ab}}$ & 5.10 & $0.001^{*}$ \\
\hline \multicolumn{2}{|c|}{$\mathrm{p}$-value } & \multicolumn{2}{|c|}{$0.023^{\star}$} & \multicolumn{2}{|c|}{$\leq 0.001^{*}$} & \multicolumn{2}{|c|}{$0.01^{*}$} & \multicolumn{2}{|c|}{$0.058 \mathrm{NS}$} & \\
\hline
\end{tabular}

*=Significant, ns=non-significant.

Different lowercase superscript letter within each row are statistically significant.

Different uppercase superscript letter within each column are statistically significant.

\section{Results of failure mode analysis:}

Figure $2 \mathrm{a}, 2 \mathrm{~b}, 2 \mathrm{c}$ and $2 \mathrm{~d}$ are representing photos for adhesive failure, mixed failure, cohesive failure in aged composite, cohesive failure in new (repaired) composite respectively. The adhesive mode will be studied specifically for standardization and simplicity. The graph in figure 3 represents the distribution of failure mode among beams. As shown, for the IM tested groups when Bond was used as an intermediate agent, both Fine and Super Fine grit bur roughened beams showed significantly lower adhesive failures percentage than those roughened with Laser, the latter was not significantly different than control at $\mathrm{P}=0.001$. On the other hand, when Flow was used as an intermediate agent, there was no statistically significant difference among all tested groups at $\mathrm{P}=0.129$, although all Flow beams suffer significantly higher adhesive failure percentage than those with Bond as intermediate agent, still Superfine surface treatment has the lowest adhesive failure percentage.

As regards the TC tested groups, there was no statistically significant difference between Fine grit and Laser with Bond as intermediate agent although both showed significantly higher adhesive failure than groups roughened with Super Fine bur at $\mathrm{P}=0.029$. In contrary, for beams with Flow as intermediate material, there were no significant difference between groups treated with Super Fine grit and Laser but both had significantly higher adhesive failure than Fine grit roughed beams at $\mathrm{P}=0.004$

Thus the null hypothesis was rejected.

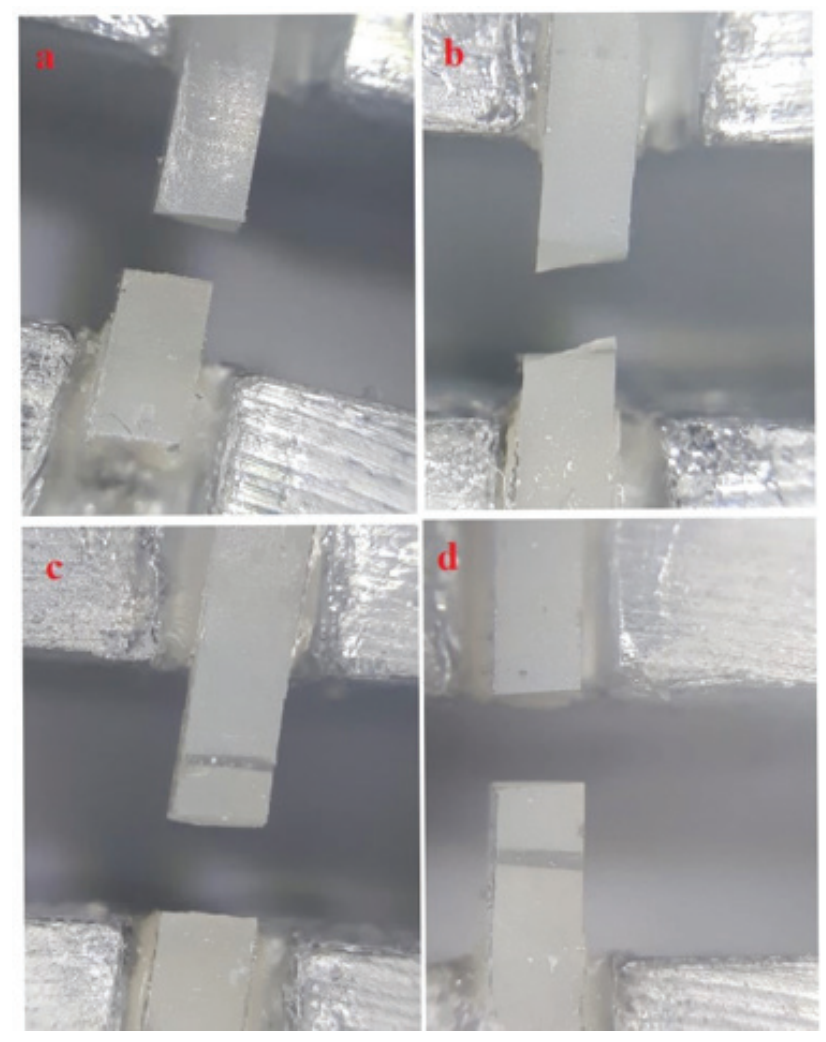

Figure 2 - Different failure modes; 1a: adhesive failure, 1b: mixed failure, 1c: cohesive failure in aged (old) composite and 1d: cohesive failure in new (repaired) composite. 


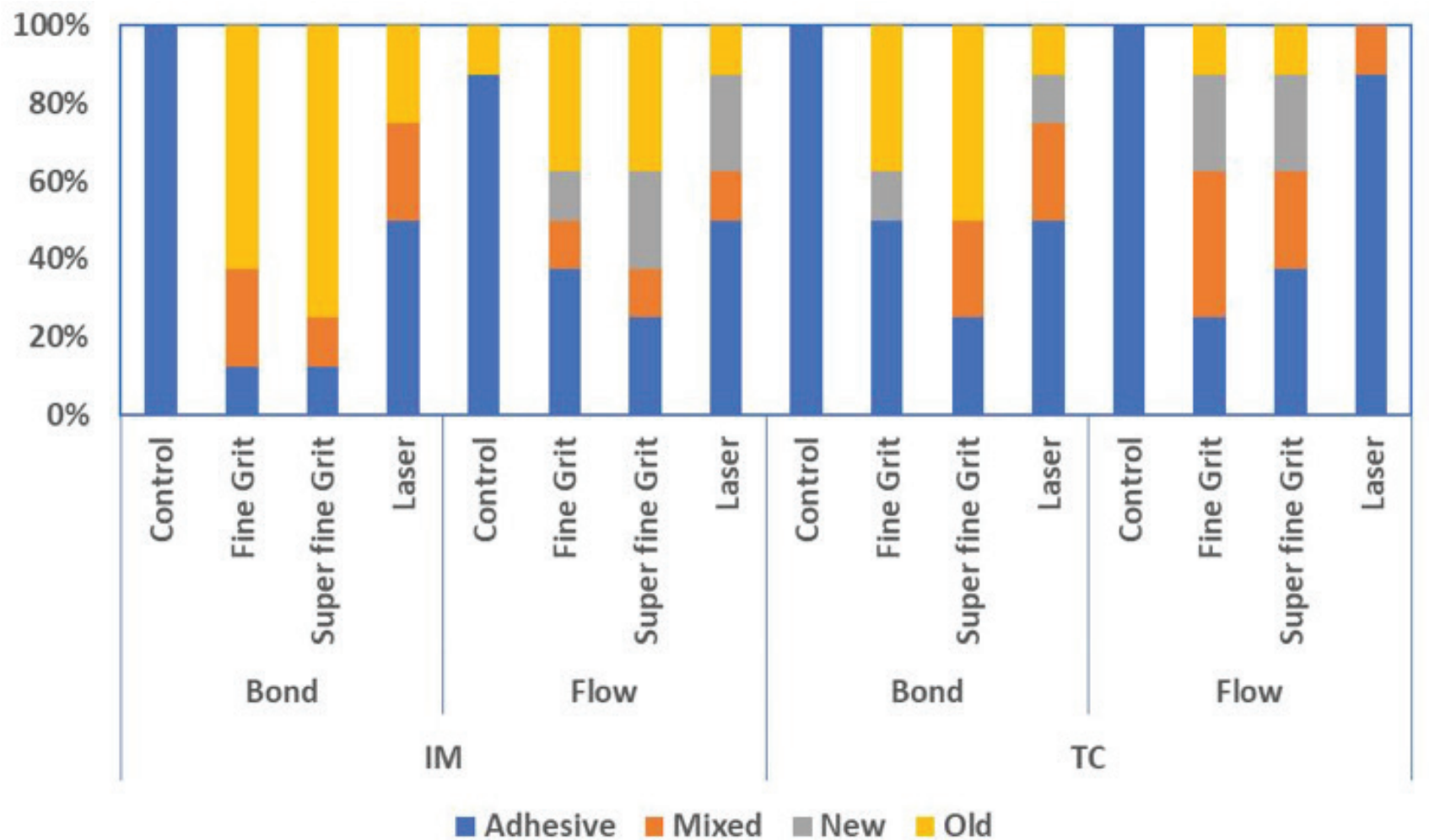

Figure 3 - Distribution of failure mode percentage.

\section{DISCUSSION}

From the clinical point of view, the presence of an oxygen inhibited layer of unpolymerized resin is very important in the bonding between two composite layers to be achieved. Following aging, composites not only undergo structural changes due to water absorption and chemical degradation but also leaching of some components lead to decrease activity of free radicals responsible for adhesion between the old and the fresh composite [3$6,16]$. Thus, the age of the restoration plays an important role in composite repair. Several studies simulate the aging process of composites by using methods such as thermocycling, storage in aqueous media, citric acid or artificial saliva $[4-6,8,13]$. In our study, we used artificial saliva as an aging media for six months to provide a more realistic simulation for repair of the old composite.

For Successful composite resin restoration repair, most studies claim that surface irregularities should be created to obtain mechanical interlocking thus increase the repair bond strength [5,6,8,9,11-13]. Though this wasn't the situation in in our study, as shown in table (II) and figure (3), as surface treatment with Super Fine Grit diamond bur showed the highest mean $\mu$ TBS and lowest adhesive failure when compared to all tested groups either IM or after TC. This can be explained as, creating irregularities may not be as important as removing surface inhibited layer and exposing the underlying unreacted monomer. Moreover, creating irregularities could induce undetected microcracks that possibly could weaken the repair bond strength and durability. This wasn't coincided with the result of other study which revealed that the Fine grit bur produced the highest repair bond strength, also they claimed that Fine grit burs generally performed better than Super Fine or Medium grit burs [18]. Another studies claimed that surface treatment of the old composite with fine grit diamond bur in conjugation with total etch bonding 
wasn't sufficient to obtain a reliable repair bond strength when compared to air abrasion $[17,25]$.

On the other hand, our results revealed that Laser surface treatment was capable of producing acceptable repair $\mu$ TBS but high percentage of adhesive failure (about 50\%) when either Bond or Flow were used as intermediate agent after IM. However, this percentage increased after TC when Flow was used as intermediate agent. Results of $\mu$ TBS was coincided with other studies which related the high repair bond strength of Erbium lasers due to selective ablation through explosive vaporization followed by hydrodynamic ejection which resulted in quick melting and changing in the volume of the melted material generating a strong expansion forces that produced pitting irregularities that increased the bonding surface area, modifying the distribution of stresses at the interface of the two bonded materials resulting in increase of the repair bond strength [14,19]. On the other hand, another study stated that using either diamond bur or Laser for surface treatment of the old composite could produce surface roughness; however, Medium grit bur produce higher efficacy due to different patterns of surface roughness as bur preparation capable of creating both macro and micro retentive features while Laser creates macro retentive areas only $[15,16]$.

This was confirmed by our observations which revealed that although Fine grit diamond bur could produce high repair bond strength but there was no statistically significant difference in the repair bond strength between Laser surface treatment and Fine grit diamond bur in all group. As reveled by mode of failure analysis; at IM the prevalence of adhesive failure was only $10 \%$ with Bond, and 30\% with Flow, after TC the prevalence of adhesive failure was $50 \%$ and $30 \%$ respectively.

As expected, the control group which received no surface treatment showed the lowest repair bond strength, which was confirmed by mode of failure analysis as the percentage of adhesive failure was nearly $100 \%$, this was consistent with the results of other studies $[14,15]$, which indicate the important role of surface treatment and micromechanical interlocking in improving the repair bond strength.

Regarding the applied intermediate agents, in the current study, using Bond showed the highest $\mu$ TBS compared to Flow for all groups as revealed in table (II) and confirmed after mode of failure analysis in figure (3).This may be due to the high viscosity of Flow as compared to Bond that result in poor wettability, this was confirmed in other study [25] which stated that treating the repaired composite, after surface treatment, with a thin layer of a high viscosity intermediate agent didn't wet the composite surface at all locations. However, other studies claimed that using flowable composite as intermediate agents in composite repair had been attributed to their stress absorbing ability and to their hydrolytic stability compared to different boding agents. They proved that flowable composite, when used as an intermediate for composite repair, was capable of producing high repair bond strength $[2,9,10]$.

It is worth mentioning that several previous studies use shear test for testing the repair bond strength. However Shear tests have been criticized due to the development of non-homogeneous stress distributions at the adhesive interface, resulting in underestimation or misinterpretation of the results due to failure in one of the substrates and not at the adhesive zone $[5,11]$. Subsequently, other studies had recommend using $\mu$ TBS testing not only to ensure that the fracture occur within the adhesion zone but also to produce proper mechanism of load application, shape and thickness of the specimens thus obtain accurate results $[9,12,18,19,25]$. For this reason, in our study, $\mu$ TBS test was used for evaluating the repair bond strength.

Thermocycling had been widely used in order to simulate the stress generated due to changes in the environmental temperature so as to study restoration durability. In our study, the 
composite repair bond strength was decreased by the aging conditions of the TC in all groups regardless the used surface treatment and intermediate agent. However, TC had the least negative effect when the combination of Super Fine bur together with Bond as an intermediate agent in a total etch mode which reflect the durability of repair bond strength.

Similar results were obtained in other studies which showed a significant reduction in repair bond strength after thermocycling [5]. On the contrary, other studies proved that there was low negative effect on the repair potential after thermocycling $[2,13,16]$.

\section{CONCLUSIONS}

Within the limitation of our in-vitro study and as regard to the used materials and techniques, the following conclusion can be obtained when dealing with aged composite:

1 - Surface treatment with Super Fine diamond bur, could produce high repair bond strength regardless the used intermediate agent.

2 - Total etch bonding technique using a low viscosity bond results in reliable repair bond strength.

3 - The Combination of Super Fine grit diamond bur together with Bond as an intermediate agent result in a more durable repair bond strength.

4 - In general, thermocycling significantly reduce the repair bond strength.

\section{REFERENCES}

1. Cavalcanti AN, De Lima AF,Peris AR, Mitsui FH, Marchi GM. Effect of surface treatments and bonding agents on the bond strength of repaired composites. JEsthet Restor Dent. 2007;19(2):90-8; discussion 99. doi: 10.1111//.17088240.2007.00073.x.PMID: 17374114.

2. Magni E,Ferrari M,Papacchini F,HickelR, llie N. Influence of ozone on the composite-to-composite bond. Clin Oral Investig. 2011 Apr;15(2):249-56. doi: 10.1007/s00784-009-0370-5. Epub 2010 Jan 7.PMID:20054592.

3. Rathke A, Tymina Y, Haller B. Effect of different surface treatments on the composite-composite repair bond strength. Clin Oral Investig. 2009 Sep;13(3):317-23. doi: 10.1007/s00784-008-0228-2. Epub 2008 0ct7.PMID: 18839227.
4. Kanzow P,Wiegand A, Göstemeyer G,SchwendickeF.Understanding the management and teaching of dental restoration repair: Systematic review and meta-analysis of surveys. J Dent. 2018 Feb;69:1-21. doi: 10.1016/j. jdent2017.09.010. Epub2017 Sep 21.PMID:28943362.

5. Kanzow P, Wiegand A, Schwendicke F, Göstemeyer G. Same, same, but different? A systematic review of protocols for restoration repair.J Dent. 2019 Jul;86:1-16. doi:10.1016/j.jdent2019.05.021. Epub 2019 May 17.PMID:31108118.

6. Ozcan M, Cura C, Brendeke J. Effect of aging conditions on the repair bond strength of a microhybrid and a nanohybrid resin composite. J Adhes Dent. 2010 Dec;12(6):451-9. doi:10.3290/j.jad.a17857.PMID: 20157647.

7. Özcan M, Corazza PH,Marocho SM,Barbosa SH,Bottino MA. Repair bond strength of microhybrid, nanohybrid and nanofilled resin composites: effect of substrate resin type, surface conditioning and ageing. Clin Oral Investig. 2013 Sep:17(7):1751-8. doi: 10.1007/s00784-012-0863-5. Epub 2012 0ct 19. PMID: 23081754.

8. YesilyurtC, Kusgoz A, Bayram M,Ulker M. Initial repair bond strength of a nano-filled hybrid resin: effect of surface treatments and bonding agents. J Esthet Restor Dent. 2009;21(4):251-60. doi: 10.1111/.1.1708-8240.2009.00271.x. PMID: 19689724.

9. Blum IR, Lynch $C D$, Wilson NH. Factors influencing repair of dental restorations with resin composite. Clin Cosmet Investig Dent. 2014 0ct 17;6:81-7.do:: 10.2147/CCIDES53461.PMID:25378952; PMCID:PMC4207439.

10. Eren D, Doğan CA, Bektaş Ö.̈.Effect of Different Surface Treatments and Roughness on the Repair Bond Strength of Aged Nanohybrid Composite. Photobiomodul Photomed Laser Surg. 2019 Aug;37(8):473-482. doi:10.1089/ photob.2018.4585. Epub 2019 May 13.PMID:31081715.

11. Palasuk J,PlattJA, Cho SD, Levon JA, Brown DT, Hovijitra ST. Effect of surface treatments on microtensile bond strength of repaired aged silorane resin composite. Oper Dent. 2013 Jan-Feb;38(1):91-9. doi:10.2341/11-057-L. Epub 2012 Jul 25. PMID:22830537.

12. Rodrigues SA Jr,Ferracane JL, Della Bona A. Influence of surface treatments on the bond strength of repaired resin composite restorative materials. Dent Mater.2009 Apr;25(4):442-51. doi: 10.1016/j.dental.2008.09.009. Epub2008 Nov 22.PMID: 19027938.

13. Batista GR, Kamozaki MB, Gutierrez NC, Caneppele TM, Rocha Gomes Torres C. Effects of Different Surface Treatments on Composite Repairs. J Adhes Dent. 2015 Aug;17(5):421-6. doi:10.3290/j.jad.a35013.PMID:26525006.

14. Valente LL, Silva MF,Fonseca AS, Münchow EA, Isolan CP,Moraes RR. Effect of Diamond Bur Grit Size on Composite Repair.J Adhes Dent. 2015 Jun;17(3):25763. doi:10.3290/j.jad.a34398.PMID:26114162.

15. Alizadeh Oskoee P,Mohammadi N, Ebrahimi Chaharom ME, Kimyai S, Pournaghi Azar F, Rikhtegaran S, Shojaeei M. Effect of Surface Treatment with Er;Cr:YSSG, Nd:YAG, and CO2 Lasers on Repair Shear Bond Strength of a Silorane-based Composite Resin. J Dent Res Dent Clin Dent Prospects. 2013;7(2):61-6. doi: 10.5681/joddd.2013.011. Epub 2013 May 30.PMID:23875082; PMCID:PMC3713862.

16. Alizadeh Oskoee P,Savadi Oskoee S, Rikhtegaran S, Pournaghi-Azar F, Gholizadeh S, Aleyasin Y,Kasrae S. Effect of Various Laser Surface Treatments on Repair Shear Bond Strength of Aged Silorane-Based Composite. J Lasers Med Sci. 2017 Fall;:8(4):186-190. doi: 10.15171//lms.2017.34. Epub 2017 Sep 27. PMID:29071025; PMCID:PMC5642167. 
17. Kiomarsi N, Saburian P,Chiniforush N, Karazifard MJ, Hashemikamangar SS. Effect of thermocycling and surface treatment on repair bond strength of composite. JClin Exp Dent. 2017 Aug 1;9(8):e945-e951. doi:10.4317/jced.53721 PMID:28936282; PMCID:PMC5601109.

18. Papacchini F,Magni E, Radovic I,Mazzitelli C,Monticellia F, Goracci C, Polimeni A, Ferrari M. Effect of intermediate agents and pre-heating of repairing resin on composite-repair bonds. Oper Dent. 2007 Jul-Aug;32(4):363-71. doi: 10.2341/06-105. PMID: 17695609.

19. Kiomarsi N, Espahbodi M, Chiniforush N, Karazifard MJ, Kamangar SSH. In vitro evaluation of repair bond strength of composite: Effect of surface treatments with bur and laser and application of universal adhesive. Laser Ther.2017 Sep 30;26(3):173-180. doi:10.5978/islsm.17-0R-12. PMID:29133964; PMCID: PMC5675907.

20. Papacchini F, Toledano M, Monticelli F, Osorio R, Radovic I,Polimeni A, GarcíaGodoy F,Ferrari M. Hydrolytic stability of composite repair bond. Eur J Oral Sci. 2007 Oct;115(5):417-24. doi:10.1111/j.1600-0722.2007.00475.x. PMID: 17850431.

21. Papacchini F,Radovic I,Magni E, Goracci C,Monticelli F,Chieffi N,Polimeni A, Ferrari M. Flowable composites as intermediate agents without adhesive application in resin composite repair. Am J Dent. 2008 Feb;21(1):53-8. PMID: 18435378.

22. BaenaE, Vignolo V,Fuentes MV, Ceballos L. Influence of repair procedure on composite-to-composite microtensile bond strength. Am J Dent. 2015 Oct,28(5):255-60.PMID:26714342.
23. Kouros P, Koliniotou-KoumpiaE, Spyrou M, Koulaouzidou E. Influence of material and surface treatment on composite repair shear bond strength. J Conserv Dent. 2018 May-Jun;21(3):251-256. doi:10.4103/JCD.JCD 37 17.PMID: 29899625; PMCID: PMC5977771.

24. Papacchini F,Dall'Oca S, Chieffi N, Goracci C, SadekFT, Suh BI, Tay FR, Ferrari M. Composite-to-composite microtensile bond strength in the repair of a microfilled hybrid resin: effect of surface treatment and oxygen inhibition. $J$ Adhes Dent. 2007 Feb;9(1):25-31.PMID: 17432398.

25. Vural UK, Gurgan S. Repair potential of a new glass hybrid restorative system. Niger J Clin Pract.2019 Jun;22(6):763-770. doi:10.4103/njcp.njcp_551_18.PMID: 31187759 .

26. Souza RO, Castilho AA, Fernandes VV, Bottino MA, Valandro LF.Durability of microtensile bond to nonetched and etched feldspar ceramic: self-adhesive resin cements vs conventional resin. J Adhes Dent. 2011 Apr;13(2):155-62. doi: 10.3290/j.jad.a18784.PMID:21594229.

27. Costa TR, Ferreira SQ, Klein-Júnior CA, Loguercio AD, Reis A. Durability of surface treatments and intermediate agents used for repair of a polished composite. Oper Dent. 2010 Mar-Apr;35(2):231-7. do: 10.2341/09-216-LPMID: 20420067

\section{Engie M. Safwat}

(Corresponding address)

33 El Bohouth St.(Ex El-Tahrir), Dokki, Cairo 12311, Egypt. Date submitted: 2020 Mar 30

E-mail: engie_safwat@hotmail.com 